\title{
The Risks in CDO-Squared Structures
}

\author{
Andrew Adams \\ University of Edinburgh Business School, U.K. \\ Rajiv Bhatt \\ Deloitte Touche Tohmatsu India Pvt. Ltd., India \\ James Clunie \\ Scottish Widows Investment Partnership, U.K.
}

\begin{abstract}
The recent sub-prime debacle has brought 'innovative' structured credit products such as collateralized debt obligations under severe criticism. The complexity of some structured finance securities and difficulties in understanding their risks has been a common theme. This paper argues that $\mathrm{CDO}$-squared structures can be so complex as to make risk assessment difficult. By modeling a simplified CDO-squared structure using Monte Carlo simulation, two of the risks unique to such structures are examined: default location risk and overlap risk. Failure to take account of these risks during a distressed credit environment will result in greater than anticipated losses among senior CDO-squared tranches.(JEL: G11, G15, G24)
\end{abstract}

Keywords: collateralized debt obligation; CDO-squared; default location risk; overlap risk; Monte Carlo simulation

\section{Introduction}

A collateralized debt obligation (CDO) is a series of obligations that are dependent on the performance of a portfolio of underlying assets (collateral), such as commercial loans, bonds, or asset-backed securities. ${ }^{1}$ CDOs extend the technology of securitization by tranching the collateral cash flows into tailor-made notes to offer returns to

1. In the context of this paper, $\mathrm{CDO}$ refers to debt obligations collateralized by bonds or credit default swaps (CDS).

(Multinational Finance Journal, 2009, vol. 13, no. 1/2, pp. 55-74)

(C) Multinational Finance Society, a nonprofit corporation. All rights reserved.

DOI: $10.17578 / 13-1 / 2-3$ 
investors with diverse risk/return needs. Since their invention in the 1980s, CDOs have evolved into 'innovative' and complex structured products.

A more recent innovation has been the so-called CDO-squared $\left(\mathrm{CDO}^{\wedge} 2\right)$, that is a $\mathrm{CDO}$ mainly invested in tranches of other CDOs (Cifuentes, 2004). ${ }^{2}$ An example of the capital structure of a $\mathrm{CDO}^{\wedge} 2$ is given in the appendix. The first $\mathrm{CDO}^{\wedge} 2$ was structured in 1998. After a slow start, the $\mathrm{CDO}^{\wedge} 2$ market grew rapidly, largely due to a benign credit environment, relatively tight credit spreads, and investment banks' pursuit of fees.

A 'cash CDO' invests in cash markets whereas a 'synthetic CDO' invests in derivative markets. Thus, the payoffs of a cash CDO come from the actual cash flows from assets in the underlying pool. Synthetic CDOs are linked to their reference entities by credit derivatives such as credit default swaps. The payoffs of most synthetic CDOs are only affected by credit events e.g. default of the reference entities.

Similarly, a 'cash $\mathrm{CDO}^{\wedge} 2$ ' is backed by tranches of existing cash CDOs, whereas a 'synthetic $\mathrm{CDO}^{\wedge} 2$ ' is backed by a portfolio of synthetic CDOs. Generally, the underlying CDOs of a synthetic $\mathrm{CDO}^{\wedge} 2$ are created specifically for inclusion in the $\mathrm{CDO}^{\wedge} 2$, and are merely conceptual structures created to compute cash flows and values of the $\mathrm{CDO}^{\wedge} 2$. Watterson (2005) categorizes $\mathrm{CDO}^{\wedge} 2$ s further into four main types of transaction: a cash CDO that invests in investment-grade debt issued by other CDOs; a cash CDO that invests in equity securities or income notes issued by other CDOs; a synthetic CDO that uses credit derivatives to obtain credit exposure to investment grade debt issued by other CDOs; a synthetic CDO that uses credit derivatives to create customized single-tranche CDOs.

Even before the 'credit crunch' which commenced in summer 2007, regulators, credit rating agencies and financial journalists had expressed concern regarding the complexity and lack of understanding of risks in $\mathrm{CDOs}$ and $\mathrm{CDO}^{\wedge} 2 \mathrm{~s}$. Partnoy (2003) discusses the difficulties that credit rating agencies have in assigning ratings to the tranches of CDOs. A BIS Joint Forum report (2004) comments on the contribution to markets from credit derivatives, but also states that "understanding the credit risk profile of CDO tranches poses challenges to even the most sophisticated market participants". It also argues that "a CDO rating cannot possibly reflect all the dimensions of the risk of these complex

2. While the collateral pool of a $\mathrm{CDO}^{\wedge} 2$ mainly comprises tranches of other $\mathrm{CDO}$ ('inner CDOs'), asset-backed securities could also constitute part of the collateral pool. 
products." Standard and Poors (quoted in the Financial Times, 26 September 2005) claim that structured credit derivatives "do not offer the diversification-related protection that investors expect from other types of assets." Another article in the Financial Times (21 March 2006) on $\mathrm{CDO}^{\wedge} 2$ structures argues that overlaps in the underlying CDOs can increase the volatility of credit ratings on these instruments, relative to those for corporate bonds.

In 2007 and 2008, defaults have started to come through in some loans underlying residential mortgage backed securities and November 2007 saw the first $\mathrm{CDO}^{\wedge} 2$ to experience an event of default (Lancer Funding II). Large write-downs have been made by banks in 2008 for $\mathrm{CDO}, \mathrm{CDO}^{\wedge} 2$ and other structured finance securities, and there have been high profile executive resignations.

Academic research on CDOs has largely focused on modeling correlated defaults and valuation of CDO tranches although Duffie and Garleanu (2001) provide a comprehensive risk analysis of CDOs. More recently, a number of papers have looked at the difficulties faced by rating agencies in evaluating the risks of CDOs. Mason and Rosner (2007) show that the big three rating agencies are often confronted with an array of conflicting incentives, which can affect choices in subjective measurements of risk. Hu (2007) argues that the changing distribution of CDO assets and the different credit cycles to which these assets have been subjected make it difficult to interpret the average statistics computed for the overall CDO sector during a short data sample period that covers only a small part of the credit cycle for each asset type.

As regards $\mathrm{CDO}^{\wedge} 2$ structures, $\mathrm{Li}$ and Liang (2005) provide a framework to value $\mathrm{CDO}^{\wedge} 2 \mathrm{~s}$ consistently with the valuation of the underlying CDOs, Baheti et al (2005) present a quasianalytical framework for valuing $\mathrm{CDO}^{\wedge} 2$ structures and the following two papers analyze the risks in a $\mathrm{CDO}^{\wedge} 2$.

A key finding from our earlier work (Bhatt, Adams and Clunie, 2005) was that the complexity of some structured finance securities makes it difficult to understand their risks. A central prediction was that similarly-rated tranches of $\mathrm{CDO}^{\wedge} 2$ securities could have very different risk profiles. The large write-downs in some but not all highly rated $\mathrm{CDO}$ and $\mathrm{CDO}^{\wedge} 2$ tranches in 2008 has indeed shown that tranches with similar credit ratings can have very different risk profiles.

Metayer (2006) studies the risk of a $\mathrm{CDO}^{\wedge} 2$, highlighting the complex relationships between the dependence structure of the underlying assets in the inner CDOs, the level of subordination of the $\mathrm{CDOs}$ and the performance of the $\mathrm{CDO}^{\wedge} 2$ itself. The pitfalls of different 
key risk indicators used as industry standards are also discussed. Exhibit 13 of the paper shows that the risk of senior tranches of both investment grade and non-investment grade $\mathrm{CDO}^{\wedge} 2 \mathrm{~s}$ increase with increase in overlap.

Monte Carlo simulation (MCS) has already been used for CDO valuation e.g. FinCad software (FinCad, 2008). The aim of this paper, however, is to show how building a model of a $\mathrm{CDO}^{\wedge} 2$ structure and undertaking MCS can assist in assessing the risks within $\mathrm{CDO}^{\wedge} 2$ structures. The focus of the paper is on understanding and highlighting the nature of the risks, rather than on tranche valuation or risk quantification. This work should be of interest to $\mathrm{CDO}^{\wedge} 2$ investors, credit analysts and financial regulators.

The model is of a simplified cash $\mathrm{CDO}^{\wedge} 2$ invested in senior debt tranches of CDOs with a collateral pool consisting of corporate bonds. The simulations show how the location of a defaulting bond influences risk in a $\mathrm{CDO}^{\wedge} 2$. It is also shown that if a bond is held in more than one $\mathrm{CDO}$, overlap risk can develop in a $\mathrm{CDO}^{\wedge} 2$. Thus, to understand the risks in $\mathrm{CDO}^{\wedge} 2$ structures, investors and credit analysts must study the location of each underlying 'credit', and monitor whether a 'credit' is held in more than one underlying CDO.

\section{Structural Characteristics of a $\mathrm{CDO}^{\wedge} 2$}

Figure 1 illustrates a $\mathrm{CDO}^{\wedge} 2$ structure. At the top of the figure is the $\mathrm{CDO}^{\wedge} 2$ itself, which is divided into several tranches. Directly below this are a series of CDOs ('inner CDOs'). The $\mathrm{CDO}^{\wedge} 2$ invests in the highlighted tranches within these inner CDOs. Below these inner CDOs are a series of 'reference entities', or underlying credits. Each inner CDO invests in a number of these reference entities.

The lower and upper bounds of a tranche are known as the Attachment Point (AP) and Detachment Point (DP) respectively. DP less AP equals the tranche size. The maximum loss a tranche can bear is equal to its tranche size. The AP of a tranche also denotes the extent of subordination of that tranche. In figure 1, for example, if the notional value of the left most ('first') inner CDO is $\$ 100 \mathrm{~m}$ then the AP of the equity tranche is 0 , the AP of the mezzanine tranche is $\$ 5 \mathrm{~m}(5 \%$ of $\$ 100 \mathrm{~m})$ and the AP of the Senior tranche is $\$ 10 \mathrm{~m}(10 \%$ of $\$ 100 \mathrm{~m})$.

For the first inner CDO, when losses in the collateral pool (reference entities) exceed $\$ 5 \mathrm{~m}$, the equity tranche gets totally exhausted, and the mezzanine tranche starts bearing the losses until the losses in the collateral pool reach $\$ 10 \mathrm{~m}$. Losses beyond $\$ 10 \mathrm{~m}$ in the collateral pool 


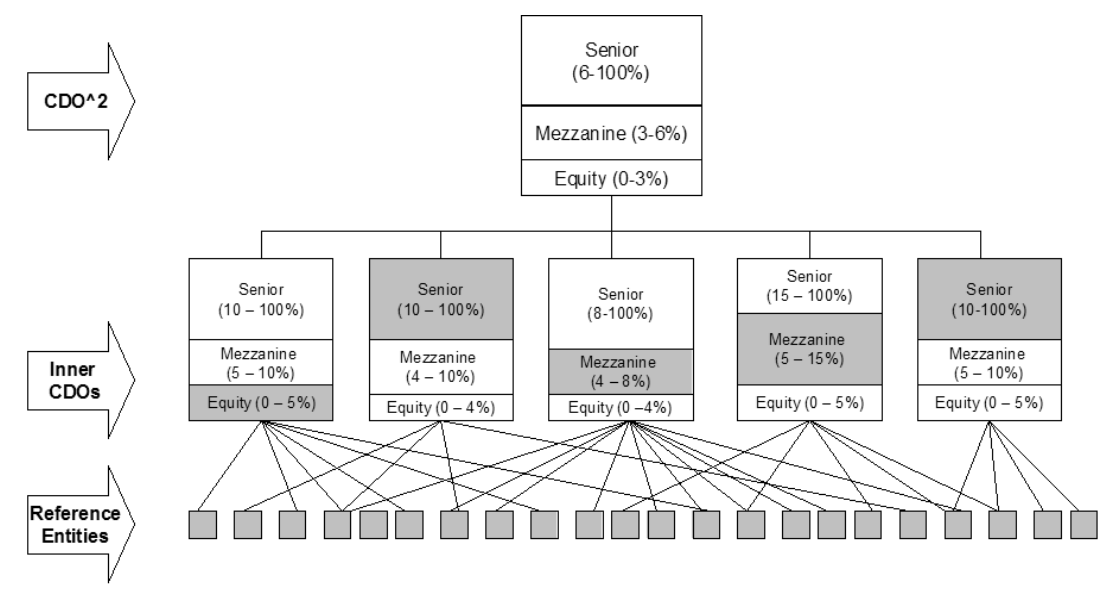

FIGURE 1.- $\mathrm{A} \mathrm{CDO}^{\wedge} 2$ structure

are borne by the Senior tranche.

More than one inner CDO could be invested in the same reference entity, as shown in figure 1 by the various lines linking the inner CDOs to the reference entities. A typical $\mathrm{CDO}^{\wedge} 2$ might reference as many as 1000 corporate names (Gilkes and Drexler, 2003). ${ }^{3}$ Given a limited universe of investment grade credits, it is highly likely that some corporate entities are referenced by more than one inner CDO. ${ }^{4}$ This overlapping of reference entities has implications for the risk characteristics of a $\mathrm{CDO}^{\wedge} 2$.

\section{III. $\mathrm{CDO}^{\wedge} 2$ Model}

While risks in a $\mathrm{CDO}^{\wedge} 2$ are largely a function of the risks in inner CDOs, there are other risks that relate to the unique structure of a $\mathrm{CDO}^{\wedge} 2$. To capture the essential features of a $\mathrm{CDO}^{\wedge} 2$, the model considers a $\mathrm{CDO}^{\wedge} 2$ that invests in tranches of two inner CDOs, namely CDO1 and CDO2. Each inner CDO has three tranches: an equity

3. Entities could be referenced through direct investment in bonds (as in a cash $\mathrm{CDO}^{\wedge} 2$ ) or through investments in $\mathrm{CDS}$ (as in a synthetic $\mathrm{CDO}^{\wedge} 2$ ).

4. Mahadevan et al (2005) estimate that the global credit investor has access to approximately 1200 investment grade credits. Also, Metayer (2006) argues that, given the most liquid corporates in the credit default swap market number about 500, it is highly likely that each name will appear in more than one CDO tranche. 


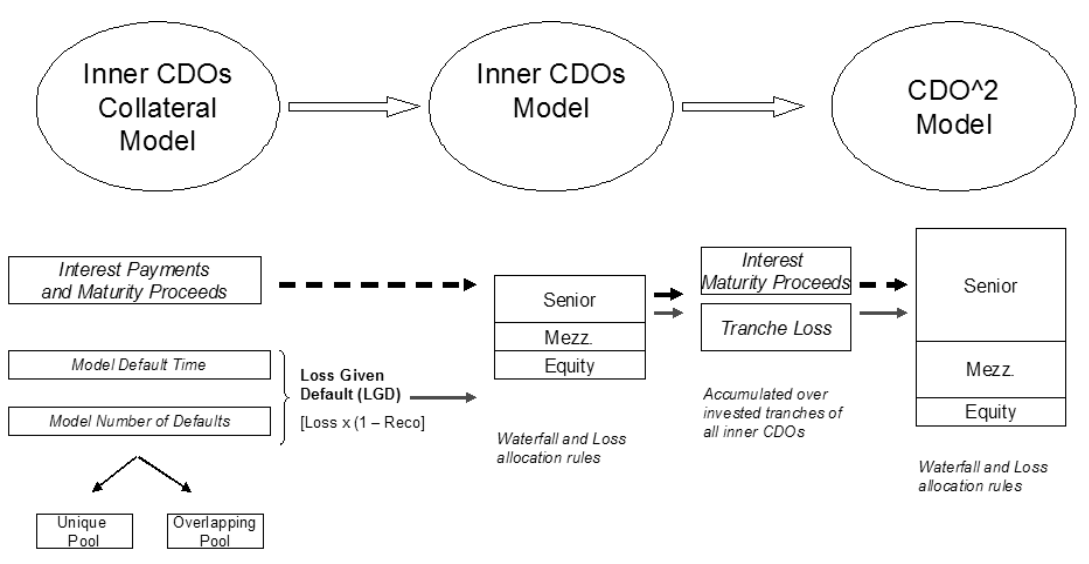

FIGURE 2.- Interaction between the three sub-models

tranche, a mezzanine tranche and a senior tranche. The $\mathrm{CDO}^{\wedge} 2$ is invested in the senior tranche of CDO1 and the senior tranche of CDO2.

It is assumed that the inner CDOs are 'Cash CDOs' with a collateral pool comprising equally-weighted and similar-rated corporate bonds ('reference entities'). The modeled $\mathrm{CDO}^{\wedge} 2$ is therefore a 'Cash $\mathrm{CDO}^{\wedge} 2$ '. Some reference entities form part of the collateral pools of both inner CDOs. These entities are referred to as 'overlaps'.

The $\mathrm{CDO}^{\wedge} 2$ model can be segregated into three sub-models which are: Inner $\mathrm{CDO}$ collateral model, Inner $\mathrm{CDO}$ model, and $\mathrm{CDO}^{\wedge} 2$ model. Figure 2 illustrates the linkages between these three sub-models. Interest payments, default losses and maturity proceeds from the collateral pool flow to the inner CDO and are allocated to the tranches of the inner $\mathrm{CDO}$ according to given priority rules. Interest payments, tranche losses and maturity proceeds of all the invested tranches (senior tranches in this illustration) are then accumulated and allocated to the $\mathrm{CDO}^{\wedge} 2$ tranches according to given priority rules.

For the collateral pool, it is assumed that: the term structure of interest rates is flat; defaults occur only once during the pool's weighted average life; defaults occur at the end of a period; recovery occurs in the same time period as the default; default time is chosen randomly between time 0 and the collateral's weighted average life; defaults occur

5. Both cash CDOs and synthetic CDOs generally have similar characteristics related to distribution of cash flow and loss among tranches. Synthetic CDOs have CDS constituting their collateral pool. CDS in turn refer to corporate bonds. Hence insights gained by modeling a cash $\mathrm{CDO}^{\wedge} 2$ would also apply to a synthetic $\mathrm{CDO}^{\wedge} 2$. 
discretely; default time is the same for collateral pools of all inner CDOs; and the number of defaults in the collateral pool follows a uniform random distribution.

Reference entities are segregated into 1) those referenced by a particular CDO only ('Unique Pool') and 2) those that are overlapping ('Overlapping Pool'). Interest on the collateral par value outstanding at the beginning of a period is received at the end of the period. When any reference entity defaults, the collateral par value is reduced by the par value of the defaulted entity. A pre-specified fixed fraction (40\%) of the par value of the defaulting entity is recovered ${ }^{6}$ The loss given default and cash flows from the collateral pool flow into the inner CDO.

The inner CDO sub-model assumes a uniform prioritization waterfall, wherein the interest received from the collateral pool is first used to pay interest to the senior tranche and then to the mezzanine tranche. If the interest paid to a tranche is less than the interest due to that tranche, the shortfall is accrued at that tranche's coupon rate. Default losses are reduced by any excess of interest received from collateral over total interest paid to the tranches (distributable default loss). Distributable default losses are absorbed by tranches in reverse priority, i.e. from the equity to the senior tranche. Any excess cash flows (interest income and recovery amounts) from the collateral pool are accumulated in a reserve account earning a risk-free interest rate. Interest earned on the reserve account is reinvested in the same account. Funds in the reserve account are similar to a capital reserve and are not used to meet any shortfalls in interest payments to tranches during the life of the CDO. At the end of each period, the tranche par value is reduced by the par value lost due to default losses. At CDO maturity, the remaining collateral pool is liquidated at its face value at maturity, and the proceeds transferred to the reserve account. The balance in the reserve account is then used to pay off the senior and mezzanine tranches to the extent of their face values outstanding at maturity, and any residual amount is paid to the equity tranche.

For the $\mathrm{CDO}^{\wedge} 2$ sub-model, total interest received from underlying tranches and total loss flowing from the underlying tranches are the inputs required to model the cash flow and loss to $\mathrm{CDO}^{\wedge} 2$ tranches. With these inputs, the $\mathrm{CDO}^{\wedge} 2$ model is similar to that of the $\mathrm{CDO}$ model.

To analyze the risks in a $\mathrm{CDO}^{\wedge} 2$, the following measures are

6. Since the focus of our paper is not on exploring the sensitivity of tranche rating/valuation to recovery rate, recovery rate is taken to be a fixed constant prior to the experiment. A recovery rate of $40 \%$ is assumed since it has been the historic average for North America (Varma Cantor and Hamilton, 2004). 
TABLE 1. Inner CDOs Base Parameter Values

\begin{tabular}{|c|c|c|}
\hline Collateral Pool & Inner CDO1 & Inner CDO2 \\
\hline Number of reference entities & 100 & 100 \\
\hline Par value of each bond & 1 & 1 \\
\hline Weighted average coupon & $8 \%$ & $8 \%$ \\
\hline Weighted average life (years) & 10 & 10 \\
\hline Recovery rate & $40 \%$ & $40 \%$ \\
\hline Coupon frequency & Semi-annual & Semi-annual \\
\hline Number of overlapping entities & 0 & \\
\hline \multicolumn{3}{|l|}{ Tranches } \\
\hline Mezzanine Subordination & $5 \%$ & $5 \%$ \\
\hline Senior Subordination & $10 \%$ & $10 \%$ \\
\hline Mezzanine Coupon & $8.25 \%$ & $8.25 \%$ \\
\hline Senior Coupon & $8.15 \%$ & $8.15 \%$ \\
\hline
\end{tabular}

calculated:

(1)Tranche Loss is simply an absolute measure of loss

(2)Tranche Loss Rate is the fraction of the tranche size that is wiped-out due to losses

(3)Total Loss Rate for a $\mathrm{CDO}\left(\mathrm{CDO}^{\wedge} 2\right)$ is the fraction of total par value of the $\mathrm{CDO}\left(\mathrm{CDO}^{\wedge} 2\right)$ that is wiped out

These measures implicitly assume that defaults in the collateral pool occur in the first period.

\section{Monte Carlo Simulation}

Due to its structural complexities, a $\mathrm{CDO}^{\wedge} 2$ cannot easily be modeled by a systematic analytical process. But MCS can be used to model the complexities (such as subordination structures, overlaps, correlations etc) of a $\mathrm{CDO}^{\wedge} 2$ in an intuitive way. The behavior of various tranches under different default scenarios can then be observed. Such observations provide insights into the risks in a $\mathrm{CDO}^{\wedge} 2$. Bergman (2001) shows that using a sufficiently large number of trials, MCS methodology can achieve virtually the same degree of precision as a purely analytical methodology. 
TABLE 2. $\mathrm{CDO}^{\wedge} 2$ Base Parameter Values

\begin{tabular}{|c|c|}
\hline Invested Tranche & $\mathrm{CDO}^{\wedge} 2$ \\
\hline$\overline{\mathrm{CDO} 1}$ & Senior \\
\hline $\mathrm{CDO} 2$ & Senior \\
\hline \multicolumn{2}{|l|}{ Tranches } \\
\hline Mezzanine Subordination & $5 \%$ \\
\hline Senior Subordination & $10 \%$ \\
\hline Mezzanine Coupon & $8.25 \%$ \\
\hline Senior Coupon & $8.35 \%$ \\
\hline
\end{tabular}

Hypothetical but realistic base parameter values of the modeled inner CDOs and $\mathrm{CDO}^{\wedge} 2$ are shown in table 1 and table 2 respectively. It is assumed that initially that there are no overlapping entities.

Descriptive charts derived from MCS are used to understand the risks in the $\mathrm{CDO}^{\wedge} 2$. MCS is combined with scenario analysis to gain better insights into the characteristics unique to a $\mathrm{CDO}^{\wedge} 2$ (e.g. overlaps). Scenario analysis helps to gain insights into the behavior of the $\mathrm{CDO}^{\wedge} 2$ under different default patterns within the underlying collateral pools.

The risk measures defined in the previous section are functions of the default rate and default location. To understand the behavior of (and hence the risks in) the $\mathrm{CDO}^{\wedge} 2$, it is important that the simulations are representative of all possible combinations. A 1000-run simulation generates a fairly diverse combination set, which should capture the essential characteristics of the $\mathrm{CDO}^{\wedge} 2$ and all the results of this study are based on a 1000-run MCS.

\section{Results}

The Tranche Loss Rates (TLRs) for inner CDOs are sequential and monotonic. The mezzanine tranche suffers losses after the equity tranche is fully wiped out, and the senior tranche suffers losses after the mezzanine tranche is fully wiped out (hence sequential). For each tranche, TLR increases with increase in default rate, until that tranche is fully wiped out (hence monotonic). This makes it simple to estimate the TLR of CDO tranches for each additional default in the collateral pool.

Figure 3 shows that the TLRs of the $\mathrm{CDO}^{\wedge} 2$ tranches are sequential but non-monotonic. Equity and mezzanine tranches particularly show 


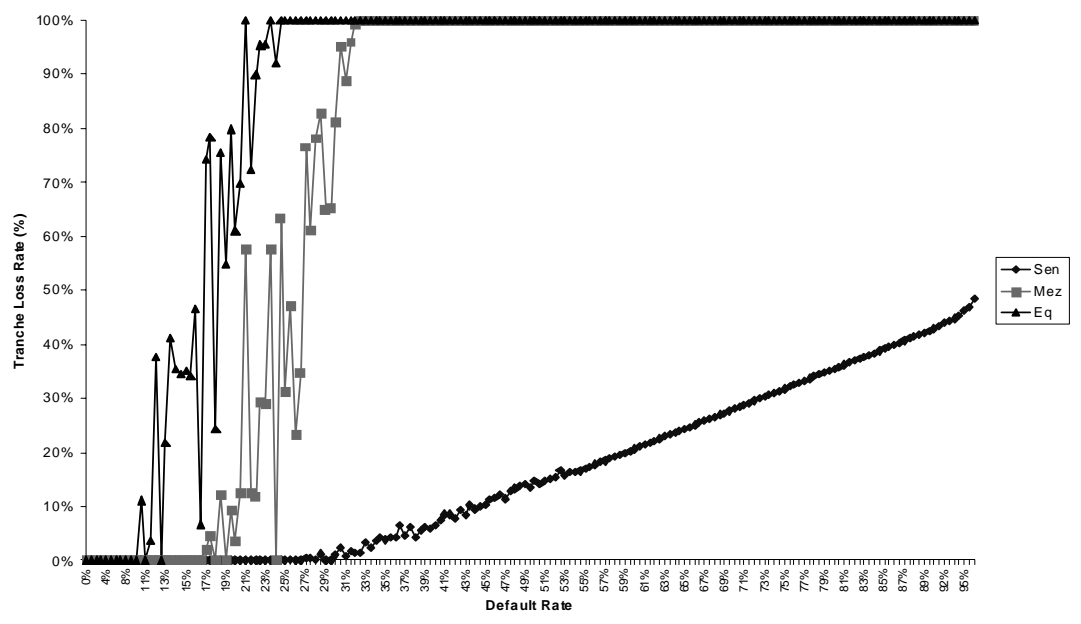

FIGURE 3.- Losses to tranches of $\mathrm{CDO}^{\wedge} 2$ are non-monotonic

prominent non-monotonic TLRs. Different TLRs can be observed for a given default rate. It follows that, unlike the TLR of inner CDOs, it is not possible to estimate the TLR of $\mathrm{CDO}^{\wedge} 2$ tranches for each additional default in the collateral pool of the inner CDOs. To investigate these non-monotonic TLRs, three data points are examined. Table 3 shows the data underlying these data points, including the $\mathrm{CDO}^{\wedge} 2$ default rate, the inner CDO default rate and tranche loss rate for each data point. ${ }^{7}$

In the base parameters, it is assumed that each inner CDO comprises 100 bonds/securities. Since there are two inner CDOs, the total securities in the inner CDO collateral pool is 200 . As the $\mathrm{CDO}^{\wedge} 2$ default rate is constant at $25 \%$ in all the three cases, a total of 50 entities out of the 200 entities of the inner pool default. However, the distribution of the 50 defaulting entities is different in each case. In case 1 , the number of defaulting entities in the inner CDO1 is 10 and in the inner $\mathrm{CDO} 2$ is 40. In case 2 , the former is 12 and the latter is 38 , and in case 3 , the defaults are equally distributed. In other words, the concentration of default in CDO2 (CDO1) decreases (increases) from case 1 to case 3. The subordination available to the senior tranche of each inner CDO is 10. In case 1 with 40 defaults, $\mathrm{CDO} 2$ bears a loss of 24 , whereas with

7. $\mathrm{CDO}^{\wedge} 2$ Default Rate $=($ Total Unique Loss $) /($ Total Unique Entities $)$, where Total Unique Loss $=$ Total Losses in CDO1 + Total Losses in CDO2 - Losses in Overlapping pool, and Total Unique Entities = Total Reference Entities in CDO1 + Total Reference Entities in CDO2 - Total Overlapping Entities. 
The Risks in CDO-squared Structures

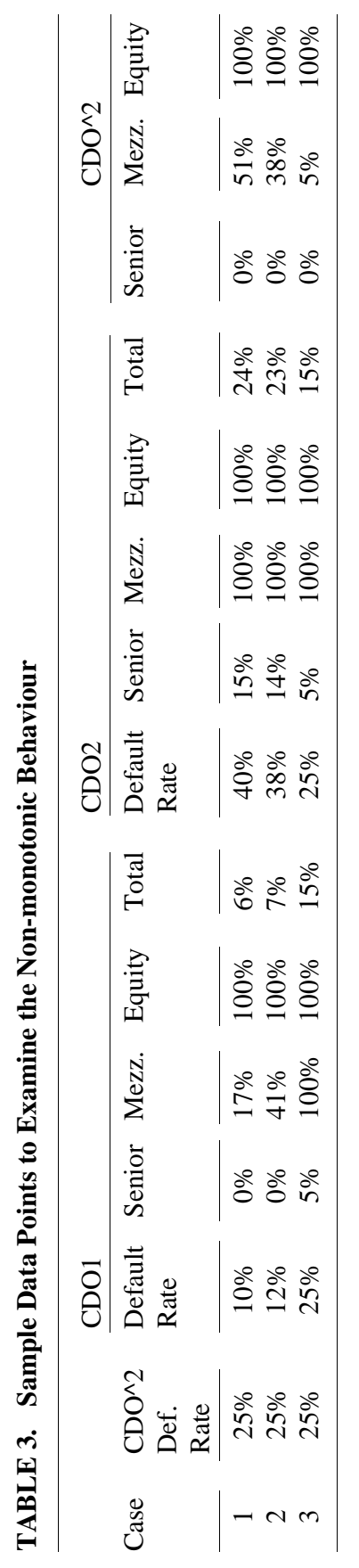


TABLE 4. Ratio of Total Loss Suffered by Inner CDO to Subordination Level of Invested Tranche

\begin{tabular}{cll}
\hline Case & CDO1 & CDO2 \\
\hline 1 & $59 \%$ & $239 \%$ \\
2 & $71 \%$ & $227 \%$ \\
3 & $149 \%$ & $149 \%$ \\
\hline
\end{tabular}

10 defaults CDO1 suffers a loss of 6 . The senior tranche of CDO2 suffers a loss of 14 [i.e. 24 less subordination (10)], whereas that of CDO1 does not suffer any loss because its subordination is not fully exhausted. Hence, total loss of invested tranches is 14, which flows to the $\mathrm{CDO}^{\wedge} 2$. The $\mathrm{CDO}^{\wedge} 2$ loses about $8 \%$ of its par value, and the equity, mezzanine and senior tranches lose $100 \%, 51 \%$, and $0 \%$ respectively of their par values.

\section{A. Default Location Risk}

Table 4 shows the total loss suffered by the inner CDOs as a percentage of the total subordination available to the invested (senior) tranche. A value greater than $100 \%$ implies subordination is fully exhausted and the invested tranche suffers losses which flow to the $\mathrm{CDO}^{\wedge} 2$.

When defaults are concentrated in one inner CDO, the probability of loss reaching the invested tranche in that inner CDO increases. This is because the subordination of invested tranches is not effectively utilized. An effective utilization of subordination would mean that total default loss of all inner CDOs is evenly spread across all inner CDOs (Case 3 in table 4). A worst-case scenario would be when all defaults occur in one inner CDO only. Figure 4 shows the par value lost by $\mathrm{CDO}^{\wedge} 2$ when the 50 defaults are distributed differently in the inner CDOs.

So for a $\mathrm{CDO}^{\wedge} 2$ investor, the distribution (location) of defaults in the inner CDOs adds a new dimension to default risk. We call this new dimension 'Default Location Risk'.

Unlike default rate, default location is difficult to model in any risk analysis and investors would be lucky if defaults are evenly distributed in all inner CDOs. Nevertheless, it might still be possible to model default location by modeling the default of each constituent of the collateral pool and identifying the default location for those defaulting constituents.

Figure 5 shows the total loss rate of the $\mathrm{CDO}^{\wedge} 2$ at different default rates in the combined collateral pool of inner CDOs. There is a lower 


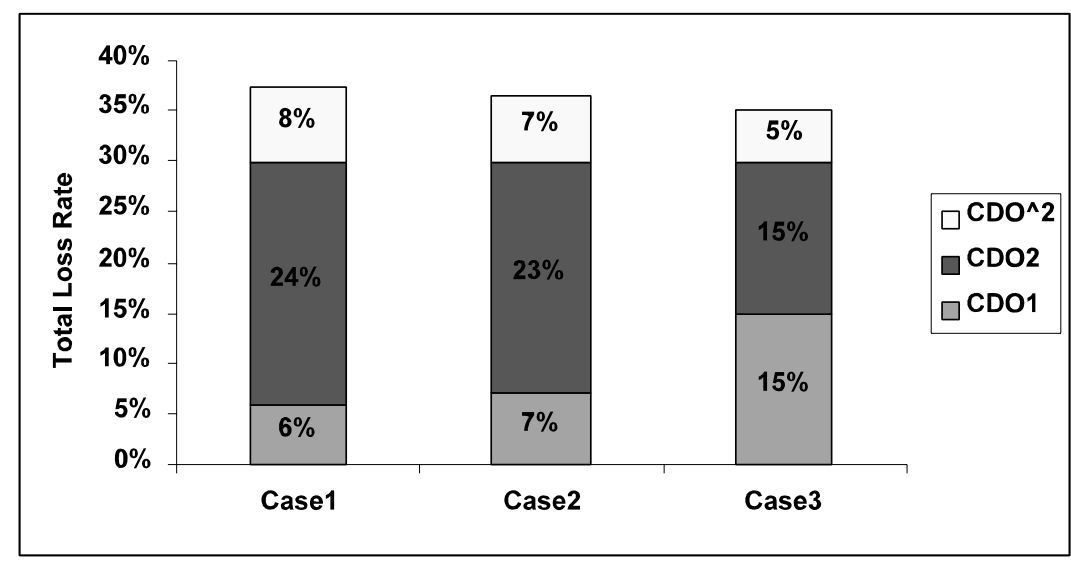

FIGURE 4.- - Loss to $\mathrm{CDO}^{\wedge} 2$ depends on location of defaults in inner CDOs

Note: 50 defaults are distributed differently in the inner CDOs. In case 1, 10 defaults occur in CDO1 and 40 in CDO2. In case 2, 12 defaults occur in CDO1 and 38 in CDO2. In case 3, 25 defaults occur in CDO1 and 25 in $\mathrm{CDO} 2$. The percentages figures shown on the bars indicate the total loss rate of each inner $\mathrm{CDO}$ and the $\mathrm{CDO}^{\wedge} 2$, assuming a recovery rate of $40 \%$. For example, total loss rate of CDO1 in case 1 is $10 \times(1-40 \%)=6 \%$. Case 3 is the best-case scenario, optimally utilizing the invested tranche subordination, and hence the $\mathrm{CDO}^{\wedge} 2$ loss rate is a minimum in that case.

bound to the total $\mathrm{CDO}^{\wedge} 2$ loss at a given default rate. This lower bound denotes the best-case default location scenario, i.e. where defaults are evenly distributed within the inner CDOs. The scatter indicates 'default location risk' i.e. when there is an uneven distribution of defaults in the inner CDOs for a given default rate. Default location risk explains why there can be different $\mathrm{CDO}^{\wedge} 2$ loss rates for a given total default rate in inner CDOs.

Could the tranche of a $\mathrm{CDO}^{\wedge} 2$ having a similar rating to that of a CDO have a different risk profile due to default location risk? To investigate this question, a hypothetical $\mathrm{CDO}^{\wedge} 2$ is simulated using S\&P's CDO Evaluator 2.4.3 ('CDO Evaluator'), which is a tool widely used by $\mathrm{S} \& \mathrm{P}$ for analyzing $\mathrm{CDO}$ and $\mathrm{CDO}^{\wedge} 2$ structures and for determining the level of subordination required by a tranche for a given $\mathrm{S} \& \mathrm{P}$ rating category. The hypothetical $\mathrm{CDO}^{\wedge} 2$ consists of six inner CDOs each of par value $100 \mathrm{~m}$. The recovery rate is assumed to be zero.

Figure 6 shows required tranche APs (as a percentage of notional) for the inner CDOs and the $\mathrm{CDO}^{\wedge} 2$ across the rating category spectrum. It compares the APs required by $\mathrm{CDO}^{\wedge} 2$ tranches when the $\mathrm{CDO}^{\wedge} 2$ is invested in inner CDOs as per each scenario in table 5. To illustrate, 


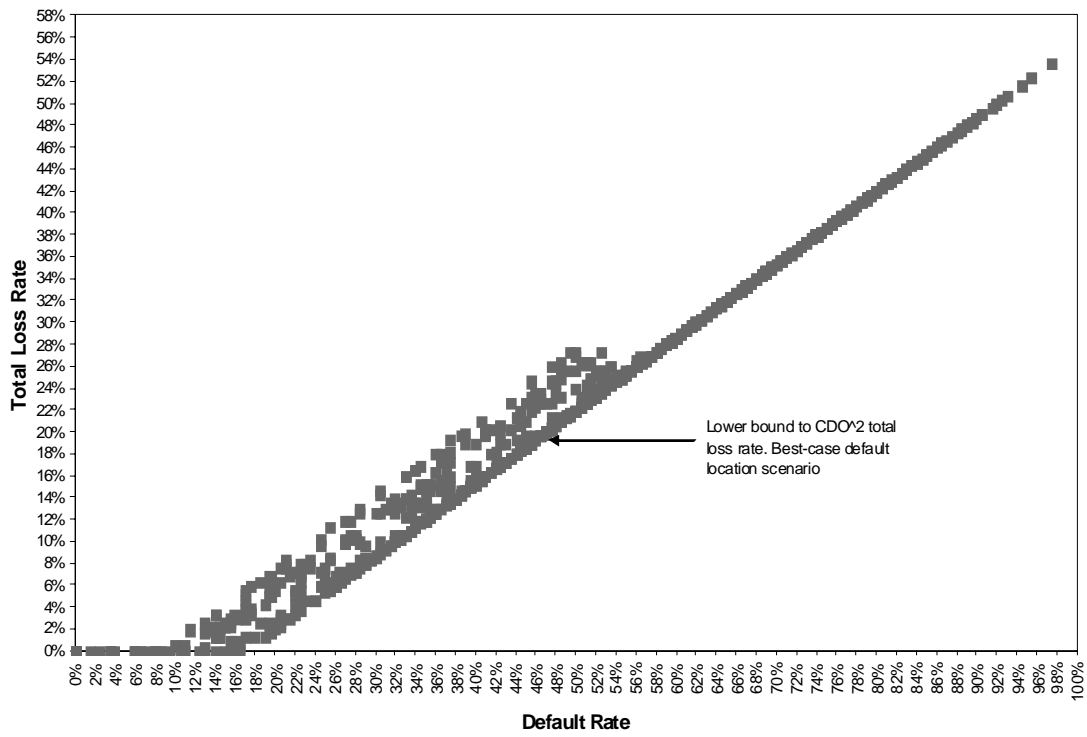

FIGURE 5.- Total loss rate of $\mathrm{CDO}^{\wedge} 2$ at different default rates.

scenario 1 implies that the $\mathrm{CDO}^{\wedge} 2$ is invested in the 'A-' rated tranche of an inner CDO. This tranche has a tranche size of $15 \mathrm{~m}$ (i.e. $(35 \%-$ $20 \%) \mathrm{X} 100 \mathrm{~m}$ ) and subordination of $20 \mathrm{~m}$ (i.e. $20 \% \mathrm{X} 100 \mathrm{~m}$ ).

From figure 6 , it can be observed that, for a given rating category, the AP (and hence the risk) of an inner CDO is different from that of $\mathrm{CDO}^{\wedge} 2$. For instance, while the inner $\mathrm{CDO}$ tranche to be $\mathrm{AA}+$ rated would require an $\mathrm{AP}$ of $40 \%$, the $\mathrm{CDO}^{\wedge} 2$ invested in the tranche as per scenario 1 above would require an AP of $50 \%$. So the risk profiles of similar-rated $\mathrm{CDO}$ and $\mathrm{CDO}^{\wedge} 2$ tranches can be very different.

It can also be observed that when a $\mathrm{CDO}^{\wedge} 2$ is invested in 'A-' rated tranches of inner CDOs each having an AP of $20 \%$ and tranche size of $15 \mathrm{~m}, \mathrm{CDO}^{\wedge} 2$ tranche to be rated $\mathrm{AA}+$ needs an attachment point of $50.67 \%$. However, when a $\mathrm{CDO}^{\wedge} 2$ is invested in $\mathrm{BBB}$ - rated tranches of inner CDOs each having a lower AP of $10 \%$ but the same tranche size of $15 \mathrm{~m}, \mathrm{a} \mathrm{CDO}^{\wedge} 2$ tranche to be rated $\mathrm{AA}+$ needs an attachment point of $82.33 \%$. So a lower attachment point of an invested tranche increases the risk of $\mathrm{CDO}^{\wedge} 2$ tranches, despite the invested tranche size being the same. The lower the AP of the invested tranche, the higher the probability that losses will flow to the $\mathrm{CDO}^{\wedge} 2$ and hence the higher the risk of $\mathrm{CDO}^{\wedge} 2$ tranches. 


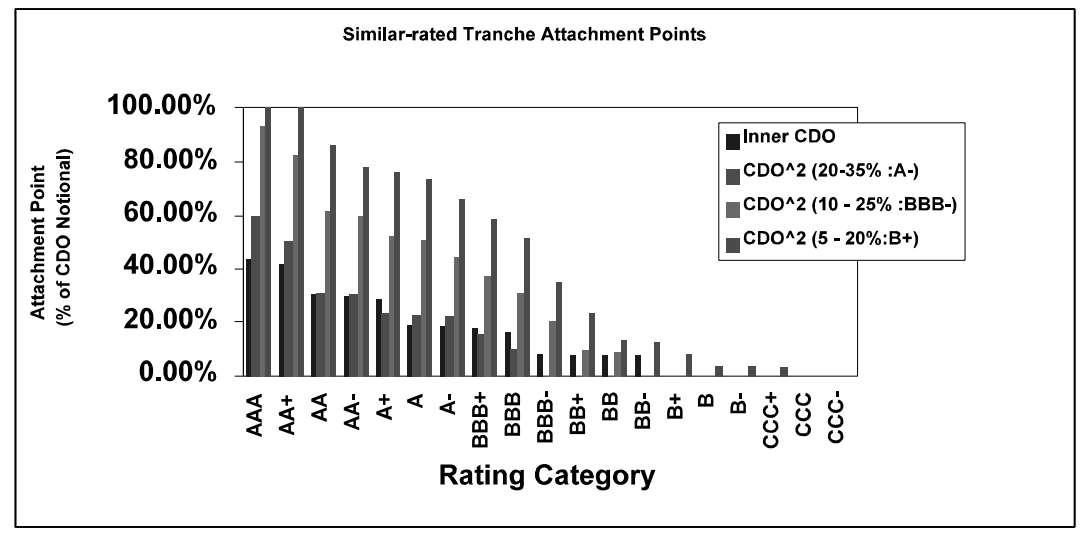

FIGURE 6.- Risks of similar-rated $\mathrm{CDO}^{\wedge} 2$ and $\mathrm{CDO}$ tranches could be different

Note: The four bars for each rating category are (from left to right): Inner $\mathrm{CDO}, \mathrm{CDO}^{\wedge} 2$ (20-35\%:A-), $\mathrm{CDO}^{\wedge} 2(10-25 \%: \mathrm{BBB}-)$, and $\mathrm{CDO}^{\wedge} 2(5-20 \%: \mathrm{B}+)$. Data underlying the chart is generated from S\&P's CDO Evaluator 2.4.3

\section{B. Overlap Risk}

The paper now investigates the impact of overlaps on a $\mathrm{CDO}^{\wedge} 2$. Two additional scenarios are created, one assuming $20 \%$ overlap, and another assuming 50\% overlap. Again, a 1000-run simulation is performed on each additional scenario. Figure 7 and figure 8 show the $\mathrm{CDO}^{\wedge} 2$ total loss rate at various unique defaults in inner CDOs under the two additional scenarios. These should be compared with figure 5 for which there was zero overlap.

Comparing these charts, it can be observed that as overlap increases, the total loss rate becomes more scattered for a given number of defaults. This is because one default in the overlapping pool is equivalent to two defaults - one in each inner CDO. So, for a given number of defaults, the total combined loss of inner CDOs when some defaults occur in the overlapping pool is greater than that when no defaults occur in the overlapping pool, or when there are no overlaps. Figure 5 shows that when there are no overlaps, the $\mathrm{CDO}^{\wedge} 2$ total loss rate increases monotonically after a certain level of unique defaults ('critical default level'). This is because at the critical default level, the entire subordination of invested tranches is exhausted and further losses to the $\mathrm{CDO}^{\wedge} 2$ would be independent of default location. When there are partial overlaps, the $\mathrm{CDO}^{\wedge} 2$ total loss rate increases non-monotonically across all levels of defaults and the lower bound on total loss rate seen 
TABLE 5. Scenarios of $\mathrm{CDO}^{\wedge} 2$ Investment in Inner CDOs

\begin{tabular}{|c|c|c|c|c|}
\hline \multirow[b]{2}{*}{ Scenarios } & \multicolumn{4}{|c|}{ Inner CDO } \\
\hline & Tranche & $\begin{array}{l}\text { CDO Evaluator } \\
\text { Rating }\end{array}$ & Tranche Size & Subordination \\
\hline 1 & $20 \%-35 \%$ & A- & $15,000,000$ & $20,000,000$ \\
\hline 2 & $10 \%-25 \%$ & $\mathrm{BBB}-$ & $15,000,000$ & $10,000,000$ \\
\hline 3 & $5 \%-20 \%$ & $\mathrm{~B}+$ & $15,000,000$ & $5,000,000$ \\
\hline
\end{tabular}

in zero-overlap scenario loses relevance. However, as overlap increases beyond $50 \%$, the scatter seen in figures 7 and 8 decreases. In the extreme case of two identical CDO tranches and thus $100 \%$ overlaps, the $\mathrm{CDO}^{\wedge} 2$ simply behaves like the $\mathrm{CDO}$ tranche and the scatter seen in figures 7 and 8 vanishes.

Figure 9 shows the standard deviation of $\mathrm{CDO}^{\wedge} 2$ total loss rate at different levels of unique defaults under $0 \%, 20 \%$ and $50 \%$ overlap scenarios. Note that the standard deviation of total loss rate increases as overlaps increase. So overlaps add a new dimension to the 'default location risk'. We call this 'overlap risk'.

\section{Conclusions}

Reflecting on the lessons for the banking industry from the events of 2007, Mervyn Davies CBE, Chairman of Standard Chartered Bank, cites three main lessons: the overwhelming importance of liquidity; secondly, the need to price properly for risk; and, thirdly, the danger of over-complexity (Davies, 2007). All three of these lessons apply to $\mathrm{CDO}^{\wedge} 2$. This paper has focused on the difficulties in pricing $\mathrm{CDO}^{\wedge} 2$ securities properly for risk if only credit-ratings are relied upon, and has highlighted some of the problems that can arise from over-complexity in structure.

A simple $\mathrm{CDO}^{\wedge} 2$ model is created and Monte Carlo Simulations carried out to understand the risks unique to a $\mathrm{CDO}^{\wedge} 2$, namely default location risk and overlap risk. The risk profiles and thus risk-adjusted returns of similarly-rated $\mathrm{CDO}$ and $\mathrm{CDO}^{\wedge} 2$ tranches can be very different. Furthermore, a lower attachment point of an invested tranche increases the risk of $\mathrm{CDO}^{\wedge} 2$ tranches, despite the invested tranche size being the same.

Failure to take account of default location risk and overlap risk will, during a distressed credit environment, result in greater than anticipated losses among senior $\mathrm{CDO}^{\wedge} 2$ tranches. It is therefore important to study 


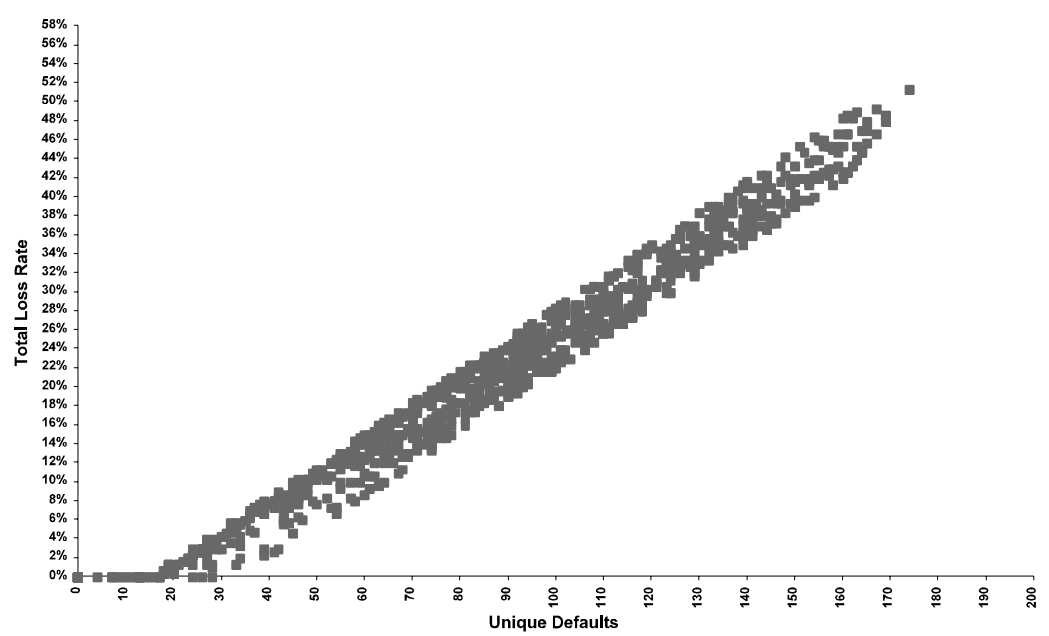

FIGURE 7.- $\mathrm{CDO}^{\wedge} 2$ Total loss rate and unique defaults $(20 \%$ overlap)

the location of underlying credits and whether they are held in more than one underlying CDO.

Further research into risk assessment techniques for $\mathrm{CDO}^{\wedge} 2$ securities could involve an extension of the modeling in this paper to include three or more internal CDOs. Alternatively, it could become generally accepted within the banking and investing community that effective risk assessment for such complex securities is extremely difficult. This could lead to substantial revision of risk-return aspirations from such products. Consequently, demand for such vehicles could diminish relative to demand for simpler vehicles for which risk is easier to model.

\section{Acknowledgements}

We are grateful to Richard Taffler for many useful comments on an earlier draft of this paper, to participants at the Multinational Finance Society Conference in Edinburgh, June 2006, for helpful suggestions and to S\&P for providing us with their CDO Evaluator model.

Accepted by: Prof. R. Taffler, Guest Editor, February 2009

Prof. P. Theodossiou, Editor-in-Chief, February 2009 


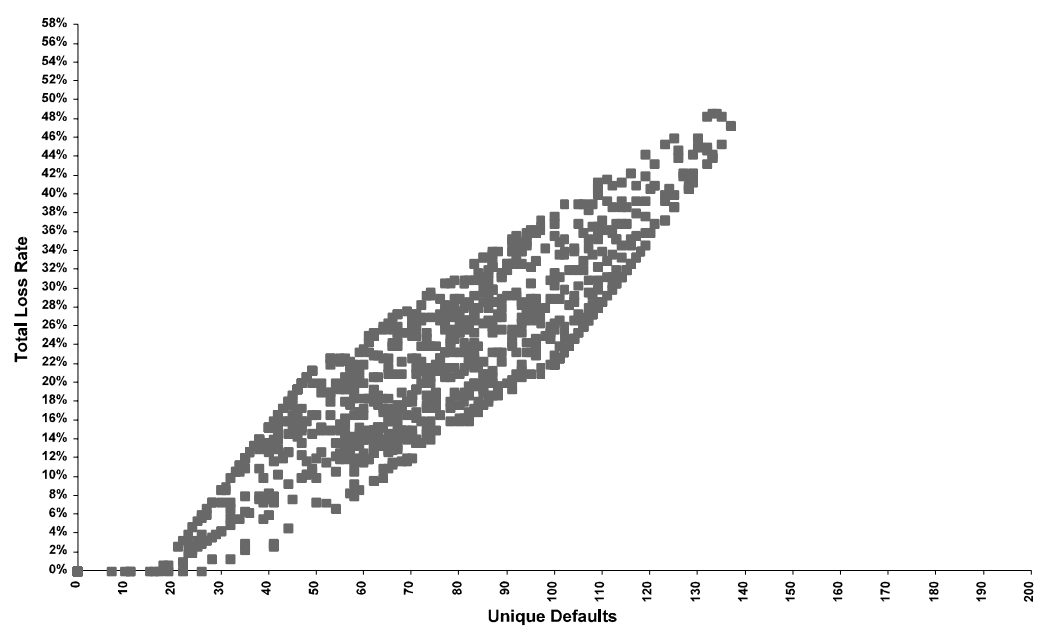

FIGURE 8.- $\mathrm{CDO}^{\wedge} 2$ Total loss rate and unique defaults $(50 \%$ overlap)

\section{Appendix}

\section{A. Example of a $\mathrm{CDO}^{\wedge} 2$ Capital Structure}

The table below shows the tranche (capital) structure of Rhodes $\mathrm{CDO}^{\wedge} 2$ launched by Dresdner Kleinwort Wasserstein on 25 June 2004.

\section{B. Tranche Structure of Rhodes $C D O^{\wedge} 2$}

Class Amount Ratings Expected Issue/re-offer Coupon price $(\mathrm{S} \& \mathrm{P} / \mathrm{F})$ maturity

SS Eu525m AAA/AAA

A1A Eu66m AAA/AAA $2009 \quad 100.00 \quad 3 E O+80 b p$

$\begin{array}{lllll}\text { A1B } & \text { Eu9m } & \text { AAA/AAA } 2009 & 100.00 \quad 4.529 \%\end{array}$

A2A Eu43m AAA/AAA $2009 \quad 100.00 \quad 3 E O+110 b p$

A2B Eu5m AAA/AAA $2009 \quad 100.00 \quad 4.829 \%$

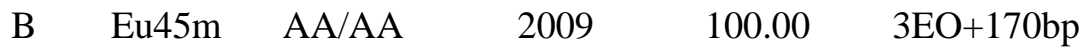

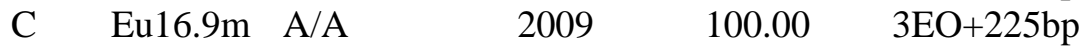

Source: Business Source Premier

Rhodes is a synthetic $\mathrm{CDO}^{\wedge} 2$ referencing 15 tailor-made (bespoke) single tranche mezzanine credit default swaps, each referencing 80 investment grade companies, with a total notional value of Eu750m. 


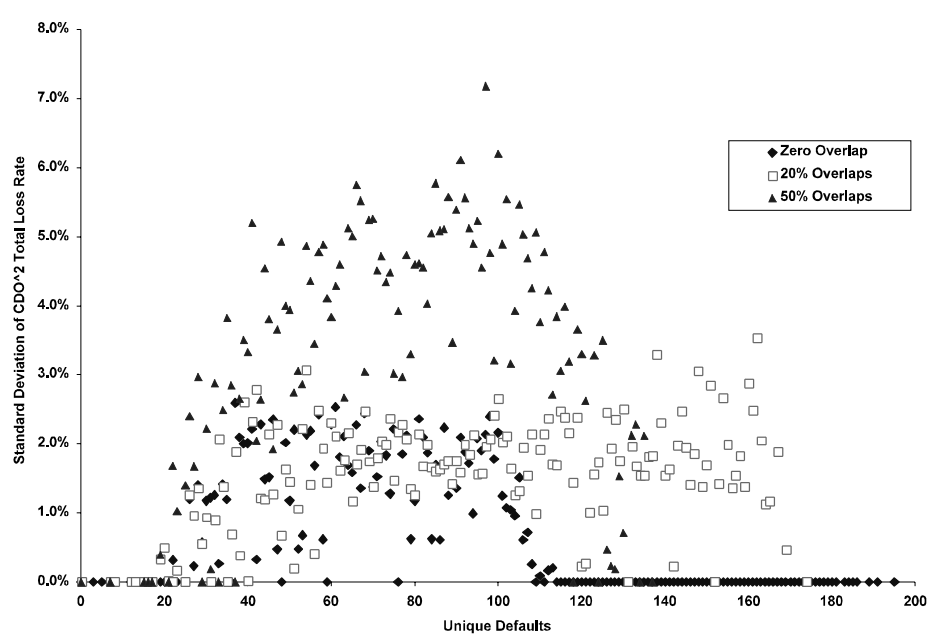

FIGURE 9.- Standard deviation of $\mathrm{CDO}^{\wedge} 2$ total loss rate at different levels of unique defaults under $0 \%, 20 \%$ and $50 \%$ overlap scenarios

About $49 \%$ of the mezzanine tranches reference US assets, around 13\% UK assets and the remainder companies from other European countries, Canada, South Korea and Australia.

The $\mathrm{CDO}^{\wedge} 2$ comprises an equity tranche (not shown in the structure), an unfunded super senior (SS) tranche and six funded fixed tranches. Two of the funded fixed tranches receive fixed interest while the other four receive a floating rate linked to the EURIBOR. The SS tranche and fixed rated tranches are rated by $\mathrm{S} \& \mathrm{P}$ and Fitch.

\section{References}

Bergman, S. 2001. CDO Evaluator applies correlation and Monte Carlo simulation to the art of determining portfolio quality. Standard \& Poor's.

Baheti, P.; Marshal, R.; Naldi, M.; and Schloegl, L. 2005. Squaring factor copular models. Risk (June). 73-75.

Bhatt, R.; Adams, A.; and Clunie, J. 2005. Hidden risks in the CDO-squared market. Working Paper 05.03 (September). Centre for Financial Markets Research: University of Edinburgh.

BIS Joint Forum. 2004 Credit risk transfer. Basel: Bank for International Settlements. 
Cifuentes, A. 2004. CDO of CDOs: investors' basic considerations. Institutional Investor 29.1 Issue 11 (November).

Davies, M. 2008. Chairman's statement. Standard Chartered annual report \& accounts. London (UK).

Duffie, D., and Garleanu, N. 2001. Risk and valuation of collateralized debt oblilgations. Financial Analyst Journal (Jan-Feb): 41-59.

FinCad. 2008. Synthetic CDO valuation using Monte Carlo simulation. FinancialCad Corporation.

Financial Times. 2005. S \& P warns of derivatives risk. September $26^{\text {th }}$.

Financial Times (March). 2006. Difficulties for US auto industry raise queries over CDOs.

Gilkes, K., and Drexler, M. 2003. Drill-down approach for synthetic CDO squared transactions.10 December. Standard \& Poor's.

$\mathrm{Hu}$, J. 2007. Assessing the credit risk of CDOs backed by structured finance securities: rating analysts' challenges and solutions (August). Available at SSRN: http://ssrn.com/abstract=1011184.

$\mathrm{Hu}, \mathrm{J}$., and Cantor, R. 2004. Measuring loss severity rate of defaulted residential mortgage-backed securities: a methodology (April). Moody's

Li, D., and Liang, M. 2005. CDO squared pricing using Gaussian mixture model with transformation of loss distribution. Working paper (September).

Mahadevan, S.; Polanskyj, P.; Tirupattur, V.; and Kumar, A. 2005. Structured credit insights: instruments, valuation and strategies. Morgan Stanley.

Mason, J., and Rosner, J. 2007. Where did the risk go? How misapplied bond ratings cause mortgage backed securities and collateralized debt obligation market disruptions (May). Available at SSRN: http://ssrn.com/abstract $=1027475$.

Metayer, B. 2006. $\mathrm{CDO}^{2}$, Correlation, overlap and subordination: implications for pricing and risk management. Journal of Structured Finance (Winter).

Partnoy, F. 2003. Infectious Greed. Profile Books. London (UK).

Tavakoli, J. 2003. Collateralised Debt Obligations \& Structured Finance: New Developments in Cash \& Synthetic Securitization. Wiley.

Varma, P.; Cantor, R.; and Hamilton, D. 2004. Default and recovery rates of Eurpopean corporate issuers.1985-2003.Moody's (March)

Watterson, P. Jr. 2005.The Evolution of CDO squared. Journal of Structured Finance (Spring). 